\title{
Perlakuan Akuntansi Pembiayaan Gadai dan Cicil Emas PT Bank Syariah Mandiri Jember
}

\author{
(Accounting Treatment of Pawn Financing and Credit Gold \\ PT Bank Syariah Mandiri Jember)
}

\author{
Neni Maulina Rahman, Sudarno*, Ahmad Roziq \\ Akuntansi, Fakultas Ekonomi dan Bisnis, Universitas Jember (UNEJ) \\ Jln. Kalimantan 37, Jember 68121 \\ E-mail: nenimaulina25@gmail.com
}

\begin{abstract}
Abstrak
This study aims to identify how determine how for mortgage financing in gold and credit gold in PT Bank Syariah branch office Jember .data collection techniques in this research is the primary data with interviews and Secondary Data From Notes or archives relating to the accounting treatment financing gold and credit Gold. The analysis used in this research is using descriptive qualitative comparative analisiss by comparing the application of the accounting treatment of mortgage financing syariah gold and credit gold with PSAK 107 and PSAK 102. The results of this study indicate that accounting treatment which includes the recognition, measurement, presentation, disclosure mortgage financing syaria gold and credit gold have with PSAK 107Accounting for Ijarah and PSAK 102, Accounting for Murrabahah.
\end{abstract}

Keywords: Pawn gold financing, Gold credit financing, PSAK No 107, PSAK No 102

\section{Pendahuluan}

Rahn adalah menjadikan harta benda sebagai jaminan hutang agar hutang itu dilunasi (dikembalikan) atau dibayarkan harganya jika tidak dapat mengembalikan hutangnya (Atthayyar,2004). Gadai Emas di Bank Syariah merupakan produk pembiayaan atas dasar jaminan berupa emas bentuk lantakan ataupun perhiasan sebagai salah satu alternatif memperoleh uang tunai dengan cepat, aman dan mudah (Bank Syariah Mandiri,2016).Gadai emas menggunakan dua akad yakni akad Ijarah dan Qardh. Selain gadai emas dalam penelitian juga membahas cicil emas. Cicil emas merupakan suatu produk atau merupakan suatu fasilitas yang dikeuarkan oleh bank Mandiri syariah umtuk pembiayaan kepilikan emas berupa emas batangan dengan jangka 2 sampai 5 tahun dengan cara mudah yaitu dengan mencicil (Bank Syariah Mandiri,2016). Pembiayaan cicil emas ini menggunakan skim akad murrabahah akad murrabahah merupakan perjanjian jual beli barang dengan menyertakan harga dan margin serta pembayarannya dapat dilakukan secara angsuran dan pengikatan agunan dengan menggunakan akad rahn. Pihak bank menjual suatu barang kepada nasabah dengan menyertakan harga yang sudah disepakati kedua belah pihak, nasabah dapat melunasi pembiayaan dengan cara diangsur tiap bulaannya .

Penelitian ini bertujuan untuk mengatahui bagaimana perlakuan akuntansi Pembiayaan gadai emas syariah dan cicil emas pada PT Bank Syariah Mandiri Cabang Jember apakah telah sesuai dengan PSAK No 107 (Akuntansi Ijarah) dan PSAK No 102 (Akuntansi Murrabahah). penelitian ini menggunakan metode penelitian kualitatif dengan analisisis deskriptif komparatif dimana dalam penelitian ini akan mengamati tentang bagaimana perlakuan akuntansi pembiayaan gadai emas dan cicil emas di Bank Syariah Mandiri Cabang Jember dan akan menganalisis praktik di Bank Syariah Mandiri dengan acuan yang telah ditetapkan.

Bank Syariah Mandiri Mempunyai banyak sekali produk pembiayaan, namun pembiayaan yang paling diminati oleh nasabah yakni pembiayaan dengan produk emas, di Bank Syariah Mandiri untuk produk pembiayaan produk emas terdapat dua jenis yakni pembiayaan dengan sistem gadai emas dan produk pembiayaan dengan sistem cicil emas. Produk pembiayaan gadai emas ini menggunakan akad Ijarah dan Qard dimana, akad ijarah digunakan untuk menghitung biaya sewa, sedangkan untuk cicil emas menggunakan akad Murrabahah yakni perjanjian yang dilakukan oleh dua orang yatiu antara bank dan nasabah dimana bank berperan sebagai penyedia pembiayaan untuk pembelian bahan baku, dan akan dibayar kembali oleh nasabah sebesar harga jual bank (pada saat bank memperoleh) pada waktu yang telah diterapkan.

\section{Rancangan Penelitian \\ Metode}

Jenis penelitian yang digunakan dalam penelitian ini adalah penelitian kualitatif dengan analisis deskriptif. Penelitian kualitatif merupakan penelitian yang memaparkan dan memahami makna yang berasal dari individu dan kelompok mengenai masalah sosial atau masalah individu. Proses penelitian melibatkan prosedur dan pertanyaan yang sudah muncul, yakni dengan mengumpulkan data dengan setting partisipan menganalisis data secara induktif, mengolah data dari yang spesifik menjadi tema umum, dan membuat penafsiran mengenai makna di balik data. (John W.Creswell,2013).

Sedangakan Penelitian desktiptif menjelaskan fenemone fenomena sosial yang ada dengan mengembangkan konsep dan menghimpun fakta, tetapi tidak melakukan pengujian hipotesis, memberikan arti atau implikasi pada suatu masalah yang diteliti (mayhuri dan zainudin, 2009).

\section{Obyek Penelitian}

Dalam penelitian ini objek penelitian adalah Bank Mandiri Syariah Tbk. Cabang jember. BSM terletak Di JL P.B Sudirman No 41-4, Jember, jawa timur.

* Corresponding author 


\section{Teknik Pengumpulan Data}

Teknik pengumpulan data dalam penelitian ini menggunakan cara Wawancara dan Dokumentasi. Wawancara merupakan sebuah pertemuan antara dua orang untuk bertukar informasi dea melalui Tanya jawab, sehingga dapat dikonstruksikan makna dalam suatu topik tertentu.Wawancara digunakan sebagai teknik pengumpulan data apabila peneliti ingin melakukan studi pendahuluan untuk menemukan permasalahan yang akan diteliti, dan juga apabila peneliti ingin mengetahui hal- hal dari responden yang lebih mendalam (Sugiyono,2015;317). Dalam penelitian ini peneliti langsung berkomunikasi dengan staf Bank Syariah Mandiri Cabang Jember agar data yang di perlukan dapat diperoleh dengan jelas.

Dokumentasi Menurut Sugiyono (2015:329) Dokumentasi adalah: Catatan perisiwa yang sudah beralalu. Dokumen ini biasanya berbentuk tulisan, gambar, atau karya - karya monumental dari seseorang. Dalam penelitian ini peneliti mendapatkan data sekunder dari Bank Syariah Mandiri Cabang Jember dalam bentuk Catatan - catatan perlakuan akuntansi terkait gadai emas dan cicil emas, brosur gadai emas, perhitungan gadai emas dan cicil emas

\section{Metode Analisis Data}

Menurut Miles dan Huberman dalam Sugiyono (2012), Analisis data kualitatif dilakukan secara interaktif melalui prose mengumpulkan data, reduksi data, uji keabsahan data, analisis data, dan penyajian data.

\section{Hasil dan Pembahasan}

\section{Hasil}

Bank Syariah Mandiri berdiri pada tahun 1999, sejalan dengan keinginan bank mandiri persero untuk membuat atau membentuk unit syariah. langkah awal yang dilakukan oleh Bank Mandiri Persero adalah mengubah anggaran dasar menjadi PT bank syariah sakinah Mandiri, pada tanggal 8 september 1999 bank syariah sakinah mandiri mengubah namanya menjadi PT Bank Syariah Mandiri atau BSM. Pada tanggal 25 Oktober 1999 Bank Negara Indonesia mengeluarkan ijin perubahan kegiatan usaha konvensional menjadi kegiatan usaha yang berdasarkan prinsip syariah .

Tujuan dari Bank Syariah Mandiri :

1. Mewujudkan pertumbuhan dan keuntungan yang bereksinambungan.

2. Mengutamakan penghimpunan dana konsumen dan penyaluran pembiayaan pada segmen UMKM

3. Mengembangkan nilai - nilai syariah universal

4. Menyelenggarakan operasioanal bank sesuai dengan standar perbankan yang sehat.

Perlakuan akuntansi untuk produk gadai emas dan cicil emas pengakuan, pengukuran, penyajian dan pengungkapan menggunakan acuan yakni PSAK 107 dan PSAK 102. Produk- produk pembiayaan Bank Syariah Mandiri Cabang Jember meliputi Pembiayaan Mudharabah, Pembiayaan Musyarakah,Pembiayaan Murrabahah, Pembiayaan Salam, Pembiayaan Istishna, Pembiayaan dengan Akad Ijarah, Pembiayaan Wakalah, Pembiayaan kafalah, Pembiayaan hawalah.

\section{Produk Gadai Emas PT Bank Syariah Mandiri Tbk Cabang Jember.}

Gadai Emas Syariah atau dapat juga disebut dengan pembiayaan rahn merupakan suatu penyerahan jaminan atau hak penguasa secara fisik atas barang berharga yang dimiliki calon nasabah berupa emas kepada bank sebagai jaminan atas pembiayaan yang diterima. Produk yang pertama kali keluar untuk jenis emas di bank mandiri syariah yaitu gadai emas. Gadai emas merupakan suatu produk pembiayaan yang dikeluarkan oleh bank syariah mandiri dengan tujuan untuk membantu masyarakat yang membutuhkan dana cepat dengan jaminan perhiasan dan emas lantakan.

Gadai emas syariah pertama muncul di Bank Syariah Mandiri Cabang Jember pada tahun 2003, gadai emas syariah Ini termasuk kedalam golongan pembiayaan dikarenakan fungsinya sendiri yaitu digunakan untuk membantu nasabah yang membutuhkan uang secara cepat dengan cara menggadaikan barang (emas) yang dimiliki, gadai emas dapat dimanfaatkan oleh masyrakat yang membutuhkan dana jangka pendek dan sangat mendesak. Bank mandiri syariah menjadikan emas menjadi 2 golongan, golongan A untuk jenis emas perhiasan dan golongan B untuk jenis emas logam mulia, dinar, dan lantakan lokal. golongan B ini fungsinya sendiri digunakan untuk investasi. produk gadai emas ini merupakan produk dari pembiayaan yang paling diminati oleh nasabah.

\section{Produk Cicil Emas Bank Syariah Mandiri Cabang Jember}

Emas batangan, lantakan, toko emas yang telah bekerja sama dengan Bank. Bank Mndiri Syariah dan PT Antam sudah memiliki kerja sama yang baik dalam dunia bisnis emas.

BSM Cicil Emas ini muncul di BSM Cabang Jember pada tahun 2003, Produk cicil emas ini dikeluarkan oleh Bank Syariah Mandiri setelah Produk Gadai Emas. BSM cicil emas ini sendiri meempunyai prosedur khusus apabila nasabah ingin memiliki emas dengan nyaman dan aman, prosedur yang dibuat oleh bank mandiri Syariah ini bertujuan agar nasabah bisa lebih mudah menikmati produk investasi emas. Prosedur prosedur yang dilakukan oleh Bank kepada nasabah yaitu sebagai berikut :

1. Calon nasabah cicil emas harus datang langsung ke Bank Mandiri Cabang Jember yaitu dengan membawa Kartu identitas nasabah. Setelah syarat syarat diiajukan nasabah mengisi formulir permohonan cicil emas.

2. Setelah formulir diisi calon nasabah akan dijelaskan tentang produk cicil emas oleh pihak bank kepada nasbah.

3. Pihak bank akan membuatkan nota analisa pembiayaan oleh bagian marketing officier yang akan diserahkan kepada kepala cabang BSM untuk disetujui.

4. Marketing officier menentukan diterima atau di totalnya cicil emas yang lalu akan di infomasikan kepada nasbah.

5. Bila cicil emas sudah diterima, maka officier akan menghitungpembiayaan yang akan diterima oleh nasbah, menghitung ,biaya adminisrasi, biaya materai, dan biaya asuransi emas.

6. Pencairan,, disertai dengan pembayaran biaya adminitrasi secara tunai sesuai dengan yang telah di tentukan oleh pihak bank dengan nasabah. 


\section{Pembahasan}

Perlakuan Akuntansi Gadai Emas Syariah di Bank
Syariah Mandiri Cabang Jember. Pengakuan Gadai Emas

Bank Syariah Mandiri untuk produk pembiayaan gadai emas mempunyai prosedur yang sesuai dengan prinsip syariah, dimana pihak bank akan mengakui emas yang digadaikan pada saat terjadinya akad (perjanjian antara kedua belah pihak), dimana pihak bank akan mencairkan dana sebesar pokok pinjaman, dan biziter (pemutus pembiayaan) akan memberikan Jumlah pembiayaan (pinjaman dari menggadaikan emas) kepada nasabah, pembiayaan terjadi setelah pihak bank menandatangani, dan hal ini sudah sesuai dengan kesepakatan bersama anatara pihak bank dan nasabah.

Pengakuan yang dilakukan oleh Bank Syariah Mandiri ini sudah sesuai dengan PSAK No 107 dimana di dalam PSAK No 107 untuk pengakuan menyatakan bahwa untuk pembiayaan gadai emas diakui sebesar nilai yang dipinjamkan dan pada saat terjadinya. Berikut perhitungan dan jurnal yang dilakukan oleh Bank Syariah Mandiri Pembiayaan $=$ Taksiran $\mathrm{x}$ nilai pembiayaan $=\mathrm{RP} 3.400 .000$ $\mathrm{X} 80 \%=\mathrm{Rp} 2.720 .000$

Pada saat terjadinya akad pembiayaan Bank menjurnal

Dr Pembiayaan Gadai/qardh

Rp 2.720.000

Cr Rekening Nasabah

Rp 2.720 .000

\section{Pengakuan Pendapatan Sewa}

Bank Syariah Mandiri akan mengakui pendapatan sewa yaitu pada saat bank menerima pembayaran dari nasabah atas biaya sewa emas yang digadaikan. Biaya sewa yang dikenakan di bank syariah Mandiri yaitu biaya pemeliharaan atas emas yang digadaikan atau emas yang disimpan di bank Syariah Mandiri.

Berikut jurnal yang dilakukan oleh bank syariah Mandiri atas pendapaan sewa

Dr Kas

Rp 168.640

Cr Pendapatan jasa sewa tempat

Rp 168.640

Pendapatan sewa diterima oleh Bank Syariah Mandiri pada saat akhir transaksi yakni pada saat barang atau emas yang digadaikan diserahkan kepada nasabah.

\section{Pengukuran Gadai Emas Syariah}

pengukuran gadai emas akan diukur apabila barang gadai telah disetujui oleh pihak bank, dan barang gadai telah diterima oleh bank, pembiayaan gadai emas akan diukur sebesar nilai nominal yang diberikan kepada nasabah. Pengukuran gadai emas syariah diukur menggunakan dasar pengukuran historical cost. Hal ini telah sesuai dengan Prinsip Syariah.

\section{Penyajian Laporan Keuangan Gadai Emas di Bank Syariah Mandiri}

Penyajian laporan keuangan gadai emas syariah dapat dilihat dalam laporan keuangan BSM pusat yang dapat dilihat di dalam laporan keuangan bagian laba rugi komprehensif dan laporan posisi keuangan BSM. Gadai emas masuk kedalam laporan posisi keuangan dan laba rugi komprehensif dengan nama akun ijarah. Dalam Laba rugi komprehensif telah dipaparkan dengan jelas tentang total pendapatan ijarah, dimana BSM memaparkan pendapatan ijarah yang disajikan secara total bersih (neto), hal ini terdapat dalam laba rugi komprehensif bank mandiri syariah tahun 2015 dimana dipaparkan tentang pendapatan ijarah sebesar Rp 118.568.245.400, pendapatan ijarah tidak hanya masuk kedalam laporan keuangan bagian laba rugi komprehensif, namun transaksi ijarah ini juga masuk kedalam laporan posisi keuangan penyajian laporan keuangan bank syariah mandiri telah sesuai dengan PSAK No 107.

\section{Pengungkapan Gadai Emas Syariah di Bank Syariah Mandiri}

Bank Syariah Mandiri telah mengungkapkan tentang transksi transki yang dilakukannya ke dalam laporan keuangan BSM. dimana dalam laporan keungan bsm terdapat pengungkapan mengenai pembiayaan gadai emas syariah yang masuk kedalam produk ijarah, transksi ijarah dalam laporan keuangan BSM ini masuk kedalam akun piutang, pada laporan keuangan BSM telah mengungkapkan tentang ijarah yang masuk dalam akun piutang ijarah.Di dalam laporan posisi keuangan BSM telah menyatakan untuk piutang ijarah dibagikan kepada pihak ketiga sebesar 18.286.157.286, jumpiutang ini dikurangi cadangan penyisihan kerugian $\mathrm{Rp}$ 1.393.313.879.602, jadi total bersih piutang ijarah paa tahu 2015 sebesar $\mathrm{Rp} 33.443 .570 .733 .751$. BSM juga telah mengungkapkan berapa pendapatan dari sewa (ijarah), pendapatan dari ijarah bersih pada tahun 2015 yaitu Rp 118.568.245.400dari penejlasan diats untuk pengungkapan BSM telah sesuai dengan PSAK 107 tentang transaksi ijarah

\section{Perlakuan Akuntansi Cicil Emas di Bank Syariah Mandiri Cabang Jember}

\section{Pengakuan pada saat Perolehan}

BSM cicil emas ini menggunakan Dasar acuan PSAK 102,, emas di BSM diatas namakan sebagai aset Murrabah, pihak BSM akan mengakui barang (emas) sebagai persediaan, dan besarnya nilai emas sesuai dengan harga emas pada saat memperoleh. bsm pada saat memperoleh emas harga emas sebesar rp 12.750.000. hal ini telah sesuai dengan pernyataan PSAK 102 untuk pengkuan gadai emas yang menyatakan bahwa pada saat perolehan, aset murrabahah diakui sebagai persediaan sebesar biaya perolehan. dari penjelasan tersebut maka jurnalnya :

Dr Aset Murrabahah

Rp 12.750 .000
Cr Kas
Rp 12.750 .000

Pengakuan pada saat perolehan ini sudah sesual dengan PSAK 102 dimana dalam PSAK 102 menyatakan bahwa untuk pengakuan pada saat perolehan, aset murrabahah diakui sebagai persediaan sebesar biaya perolehan.

\section{Pengakuan Keuntungan (Margin)}

Untuk pengakuan keuntungan pihak bank akan mengakui keuntungan pada saat penyerahan aset murrabahah, pihak bank akan mengakui berapa besar keuntungannya pada saat 
pihak bank memberikan emas kepada nasabah. jurnal yang dilakukan oleh bank :

$\begin{array}{ll}\text { Dr Kas } & \text { Rp 12.750.000 } \\ \text { Dr Murrabahah } & \text { Rp 4.000.000 } \\ \text { Cr Aset Murrabahah } & \text { Rp 12.750.000 } \\ \text { Cr Margin Murrabahah } & \text { Rp 4.000.000 }\end{array}$

\section{Pengakuan Uang Muka}

Nasabah yang akan mencicil emas di Bank Syariah Mandiri akan membayarkan uang muka secara tunai kepada bank sebagai tanda nasabah melakukan pembiayaan cicil emas. Pengakuan uang muka Pihk BSM akan mengakui uang muka sebagai uang muka dari pembelian emas sebesar jumlah yang diterima. Berikut jurnal untuk pengakuan uang muka
Dr Kas

Rp 3.350.000

Cr Hutang Uang Muka Murrabahah
Cr Hutang atas Uang Muka

Rp 2.550 .000

\section{Penyajian Laporan Keuangan Bank atas Pembiayaan Cicil Emas}

Penyajian akuntansi untuk cicil emas terdapat dalam laporan keuangan BSM pusat. Dalam laporan keuangan BSM pembiayaan cicil emas masuk ke dalam produk Murrabhah yang tercantum dalam laporan posisi keuangan BSM .Pihak BSM menyajikan piutag murrabahah disajikan sebesar nilai neto yang dapat direalisasikan dan marjin murrabahah tangguhan disajikan sebagai pengurang dari piutang murrabahah. Akun murrabahah selain masuk kedalam laporan posisi keuangan, akun murrabahah juga masuk kedalam laporan laba rugi komprehensif BSM .

Penyajian laporan keuangan atas produk pembiayaan cicil emas BSM telah sesuai dengan PSAK No 102.

\section{Pengungkapan Laporan Keuangan Bank Syariah Mandiri}

Berikut ini akan dijelaskan tentang pengungkapan laporan keuangan Bank Syariah Mandiri dalam laporan keuangan BSM telah mengungkapkan tentang transaksi Murrabahah. Pada laporan keuangan BSM tepatnya di catatatan atas laporan keuangan BSM telah diungkapkan berapa total piutang murrabahah pada tahun 2015, dan jangaka waktu murrabahah, dan berapa jangka waktu pembiayaan murrabahah. Pembiaayaan Murrabahah di BSM antara 1-5 tahun. Untuk pengungkapan laporan keuangan Bank Syariah Mandiri ini telah sesuaI dengan PSAK 102 tentang pengungkapan akuntansi Murrabahah.

\section{Simpulan}

Berdasarkan hasil penelitian dan pembahasan mengenai perlakuan akuntansi pembiayaan gadai emas (Rahn) dan cicil emas pada PT Bank Syariah Mandiri Cabang Jember dapat disimpulkan bahwa Untuk perlakuan akuntansi yang meliputi pengakuan, penyajian, pengungkapan pada produk pembiayaan gadai emas pada Bank Syariah Mandiri Cabang Jember telah sesuai dengan PSAK No 107 (Akuntansi ijarah) dan untuk Perlakuan akuntansi yang meliputi pengakuan, pengukuran, penyajian, pengungkapan untuk produk pembiayaan cicil emas pada Bank Syariah Mandiri Cabang Jember telah sesuai dengan PSAK No 102 (Akuntansi Murrabahah).

\section{Referensi}

BSM akan mengukur uang muka dan murrbahah yakni apabila barang dibeli oleh nasbah maka uang muka pembayaran akan diakui sebagai pembayaran piutang. Berikut contoh yang diberikan oleh BSM untuk menilai uang muka :

\section{Pengukuran Uang Muka}

Untuk menilai berapa uang muka BSM melakukan perhitungan sebagai berikut :

Uang muka untuk cicil emas $20 \%$ dari harga emas di pasran yang sedang berlaku.

harga emas : $20 \%$ x Rp $12.750 .000=\operatorname{Rp} 2.550 .000$

dari perhitungan diatas jurnalnya ;

Dr Kas

Rp 2.550.000
Abdul kadir Muhammad,. 2006. hukum peikatan alumni. Bandung.

AbdulKadir Muhammad dan Rilda Murniati.2000. Segi Hukum Lembaga Keuangan Dan Pembiayaan.Bandung: PT. Citra Aditya Bakti.

Anshori, Abdul Ghofur, 2005.Gadai Syariah di Indonesia: Konsep Implementasi dan Institusionalisasi.Cet,pertama.Yogyakarta : Gadjah Mada University Press, hal 1.

Ath-Thayyar,AbdullahbinMuhammad.,2004.Ensiklopedia Fiqh Muamalah dalam Pandangan 4 Madzhab (terjemahan). Edisipertama. Yogyakarta: Maktabah Al- Hanif

Creswell, John W. 2013. Research Design: Pendekatan Kualitatif. Kuantitatif, dan Mixe, Edisi Ketiga. Yogyakarta: Pustaka Pelajar

Dewan Standar Akuntansi Keuangan Ikatan Akuntan Indonesia.2009.Pernyataan Standar Akuntansi Keuangan No 107, Akuntansi Ijarah. Jakarta : Dewan Standar Akuntansi Keuangan Ikatan Akuntan Indonesia. [serial on line ]. http://iaiglobal.or.id/v03/standar- 
akuntansi-keuangan/pernyataan-sas-70-psak-107-akuntansi-ijarah Maret 2017].

Dewan Standar Akuntansi Keuangan Ikatan Akuntan Indonesia.2009.Pernyataan Standar Akuntansi Keuangan No 102

Akuntansi Murrabahah. Jakarta : Dewan Standar Akuntansi Keuangan Ikatan Akuntan Indonesia. [serial on line ] http://iaiglobal.or.id/v03/standar-akuntansi-keuangan/pernyataan-sas-65psak-102-akuntansi-murabahah. [30 Maret 2017] yauddin, Djuwaini. 2008 Yogyakarta: Pustaka Pelajar

Hadi,Mohammad Sholikul.2003. Pegadaian Syariah. Edisi Pertama.Jakarta: Salemba Diniyah.hal 3.

Moleong, Lexy J. 2004. Metodologi Penelitian Kualitatif. Bandung: Remaja Rosdakar 